\title{
Animalidad y subjetividad. Los animales (no humanos) como sujetos-de-derecho*
}

\author{
Juan Pablo Mañalich Raffo**
}

\begin{abstract}
RESUMEN
A propósito de la transformación recientemente experimentada por la tipificación del delito de maltrato de animales, favorablemente reconfigurado como un delito de maltrato de animal, el artículo desarrolla un argumento encaminado a defender la atribución del estatus de sujetosde-derecho a la generalidad de los animales no humanos, en cuanto seres individualmente considerados. Tras clarificar el sentido en que la noción de sujeto-de-derecho resulta definitoria de un estatus normativo distintivo, anclado a la condición individual de ser sujeto de intereses, el trabajo explora la particular relectura de la filosofía práctica de Kant en la que Korsgaard ha intentado, promisoriamente, sustentar la adscripción de derechos subjetivos a los animales no bumanos.
\end{abstract}

Maltrato de animal - derechos subjetivos - paciencia moral

\section{Animalbood and subjectivity. (Non-buman) animals as legal subjects}

\begin{abstract}
In the light of the recent transformation of the definition of mistreatment of animals, adequately reshaped as an offense of mistreatment of an animal, the paper develops an argument defending the attribution of the status of legal subjects to non-buman animals as individually considered
\end{abstract}

\footnotetext{
* Sendas versiones preliminares del presente trabajo fueron presentadas como ponencias en el Primer Congreso sobre Derecho Animal, celebrado en la Pontificia Universidad Católica de Valparaíso el pasado 11 de agosto de 2017, y en el VIII Congreso de Derecho y Cambio Social, celebrado en la Universidad Austral de Valdivia durante los días 17 y 18 de agosto de 2017; agradezco a las y los participantes en ambos foros por sus observaciones. Gratitud debo, asimismo, a Isabel Yáñez Morales, ayudante ad honorem del Departamento de Ciencias Penales de la Facultad de Derecho de la Universidad de Chile, por su valiosa colaboración en la edición del texto.

** Licenciado en Ciencias Jurídicas y Sociales, Universidad de Chile. Doctor en Derecho, Universidad de Bonn, Alemania. Profesor de Derecho Penal, Universidad de Chile. Correo electrónico: jpmanalich@ derecho.uchile.cl

Artículo recibido el 23 de agosto de 2017 y aceptado para su publicación en este número el 23 de julio de 2018.
} 
beings. After clarifying the sense in which the notion of legal subject defines a distinctive normative status, anchored to individual condition of being a holder of interests, the paper explores the particular rereading of Kant's practical philosophy upon which Korsgaard has persuasively attempted to ground the ascription of subjective rights to non-buman animals.

Animal mistreatment - subjective rights - moral patience

\section{Del maltrato de animales al maltrato de ANimal}

$\mathrm{E}$ 12 de agosto de 2017 apareció publicada en el Diario Oficial la Ley No 21.020, "sobre tenencia responsable de mascotas y animales de compañía". Entre las "disposiciones generales" contenidas en el Título X de la ley, figuran modificaciones introducidas en el Código Penal, consistentes, en lo fundamental, en la incorporación de la "inhabilidad absoluta perpetua para la tenencia de animales" al catálogo de penas previstas en la regulación penal, así como en una muy significativa transformación del sentido y alcance de la decisión de criminalización plasmada en el art. 291 bis del mismo código, que tipifica el así llamado "maltrato de animales". En este último punto se centrará, por de pronto, la indagación.

La modificación operada en el propio art. 291 bis consiste en el establecimiento de dos formas calificadas, formuladas en los nuevos incisos $2^{\circ}$ y $3^{\circ}$ del artículo en cuestión. En uno y otro caso, el criterio de calificación del delito consiste en el condicionamiento causal de un determinado resultado, consistiendo este en un "daño" para el animal, bajo el inc. $2^{\circ}$, y en "lesiones que menoscaben gravemente la integridad física o provocaren la muerte del animal”, bajo el inc. $3^{\circ}$. Más allá de la penalidad progresivamente incrementada, frente a aquella asociada a la forma básica del ahora inc. $1^{\circ}$, para una y otra variante calificada, la innovación más importante queda determinada por el hecho de que en la formulación de cada una de las dos variantes calificadas la disposición hable, en singular, "del animal", lo que contrasta con el hecho de que el ahora inc. $1^{\circ}$ siga haciendo uso de una forma plural al establecer como aparente núcleo típico el ejecutar "actos de maltrato o crueldad con animales".

El uso del adjetivo "aparente" se justifica aquí por el hecho de que esta descripción en efecto ya no expresa adecuadamente en qué consiste, a partir de la entrada en vigor de la Ley $\mathrm{N}^{\circ}$ 21.020, el núcleo típico del delito aquí considerado. Pues la introducción de las dos variantes calificadas, ya reseñadas, ha ido acompañada del establecimiento de un nuevo artículo, ubicado inmediatamente a continuación del art. 291 bis, que trae consigo una íntegra redefinición de la variante ahora básica del delito en cuestión. Dispone el nuevo art. 291 ter:

Para los efectos del artículo anterior se entenderá por acto de maltrato o crueldad con animales toda acción u omisión, ocasional o reiterada, que injustificadamente causare daño, dolor o sufrimiento al animal. 
Son varios los aspectos de la definición así formulada que contribuyen a la radical transformación de la fisonomía típica del delito punible bajo el art. 291 bis, la que tiene que ser puesta en relación, ulteriormente, con la expresa declaración, contenida en el art. 12 de la ley, de la punibilidad del así llamado "abandono de animales" bajo la norma de sanción del art. 291 bis del Código Penal ${ }^{1}$, redefinida en su alcance en los términos del ya mencionado art. 291 ter. Desde ya, es fundamental reparar en que, con arreglo a esta definición, el delito pasa a tener, inequívocamente, una estructura resultativa ${ }^{2}$. Esto se traduce en que, en su forma básica, la consumación del delito quede condicionada por la exigencia de que el comportamiento en cuestión dé lugar -de manera imputable-a un resultado de daño, dolor o sufrimiento para el animal. A este respecto debe notarse, con todo, que el hecho -indicativo de una deplorable técnica legislativa- de que la voz "daño" también sea usada, en el contexto del nuevo inc. $2^{\circ}$ del art. 291 bis, para designar el resultado de la respectiva variante calificada, sugiere que el núcleo de la variante básica del delito puede ser identificado ya sea con la producción -en su modalidad comisiva- o con la falta de impedimento o supresión -en su modalidad omisiva- de dolor o sufrimiento para el animal de que se trate.

Por su parte, la explícita formulación de una modalidad omisiva de maltrato ${ }^{3}$, en los términos ya referidos, debe ser entendida, a su vez, como descansando en la consideración de que, en congruencia con lo establecido en el art. 10 de la ley, así como en general con lo dispuesto en el art. $3^{\circ}$ de la Ley $\mathrm{N}^{\circ} 20.380$, "sobre protección de animales”, serán la o las personas responsables del bienestar del animal afectado quienes, en su condición de garantes, puedan venir en consideración como posibles autoras de la variante así construida ${ }^{4}$. Este es un antecedente de la mayor significación, en cuanto hace reconocible que la regulación asume la existencia de relaciones jurídicas cuyo contenido queda determinado por la obligación de una o más personas determinadas de preservar y asegurar condiciones de bienestar para algún animal individualmente considerado ${ }^{5}$.

${ }^{1} \mathrm{Y}$ que ha de ser puesta en relación, a su vez, con la definición de la expresión "animal abandonado", fijada en el $\mathrm{N}^{\mathrm{o}} 2$ del art. $2^{\circ}$ de la propia Ley $\mathrm{N}^{\circ} 21.020$.

2 Ello era ya predicado del delito de maltrato de animales, bajo la anterior versión del art. 291 bis, por GuZmán DALbora, 2007, pp. 236 s.

${ }^{3}$ La admisibilidad constructiva de una modalidad omisiva del delito bajo la regulación anterior es defendida por Guzmán Dalbora, 2007, pp. 237 s.

${ }^{4}$ Es importante notar, con todo, que mientras las relaciones de garantía configuradas con arreglo a la Ley $\mathrm{N}^{\circ} 20.380$ aparecen fundamentadas en el desempeño de una función de protección del animal en cuestión, el foco de la Ley $\mathrm{N}^{\circ} 21.020$ se encuentra primaria aunque no exclusivamente puesto, más bien, en el desempeño de una función de control o vigilancia del animal en cuanto fuente de peligro. Acerca de la estructura de las relaciones de garantía con relevancia jurídico-penal, en referencia inmediata a los presupuestos típicos de los delitos de omisión impropia, véase MAÑALICH, 2014a, pp. 241 ss., con referencias ulteriores.

5 Valga la precisión de que, sin que ello pueda ser debidamente fundamentado en el presente contexto, el argumento desarrollado en el texto principal asume la corrección teórica y metodológica de una concepción "objetivista" de la interpretación de la ley, sobre la base de la cual la apelación a la "voluntad del legislador" no funciona sino como una metáfora. En particular acerca de la necesidad de evitar la confusión, en la que usualmente incurren los partidarios de una concepción "subjetivista”, entre los así llamados “canon histórico" y "canon genético” de interpretación, véase Alexy, 1991, pp. 291 y ss., 294 y ss. 
Precisamente esta puntualización da con el meollo de la innovación regulativa aquí considerada. Pues el hecho de que, tanto para la modalidad comisiva como para la modalidad omisiva, el art. 291 ter identifique el objeto de referencia del comportamiento potencialmente punible con un animal individualmente considerado -así como ello resulta determinado por el uso de la forma singular- hace posible sostener que la mejor reconstrucción posible del sentido y alcance de esa misma innovación regulativa pasa por advertir que, por esta vía, la regulación ha sustituido la tipificación de un delito de maltrato de animales por un delito de maltrato de animal. Que esta precisión gramatical no se reduce a un mero juego de palabras se deja mostrar, sin más, haciendo explícitas las consecuencias que se siguen de la modificación experimentada por la correspondiente decisión de criminalización de cara a la pregunta por la individuación y la cuantificación de las instancias de realización del tipo en cuestión, en función de si son uno o varios los animales cuyo maltrato venga en consideración ${ }^{6}$. Bajo la tipificación hoy vigente, lo correcto será reconocer tantas instancias de realización del tipo como sean los animales individualmente afectados, en la forma de un concurso ideal, medial o real, según corresponda, como ello sucede, en general, tratándose de cualquier incidencia típicamente relevante en una pluralidad de personas individuales cuando el tipo en cuestión es el tipo de un delito contra un bien jurídico personalísimo ${ }^{7}$.

La pregunta que se suscita de inmediato, entonces, es la de si esta última categoría resulta estricta o siquiera aproximativamente adecuada para dar cuenta del contenido de injusto -y en tal medida, del fundamento de ilicitud- del nuevo delito de maltrato de animal. En lo que sigue quisiera presentar un argumento encaminado a ofrecer una respuesta afirmativa a la pregunta así planteada, que descansará en el esfuerzo por demostrar que hay razones poderosas para defender la adscripción del estatus normativo de sujeto-de-derecho -esto es, de titular de algún conjunto (variable y contingente) de derechos subjetivos- a un vasto grupo de animales individuales de especies distintas de la del homo sapiens ${ }^{8}$. Ello hará posible volver a poner la mirada, hacia el final, en la modificación legislativa ya reseñada, de un modo que llevará a relativizar drásticamente el progreso ético que ella pudiera representar.

En cualquier caso, tal confusión no puede servir de pretexto para que el intérprete conceda relevancia a las palabras de un agente distinto de aquel cuyas palabras son objeto de interpretación, a saber: del legislador en cuanto hablante institucional artificial; sobre esto último, véase en detalle MAÑALICH, 2017, pp. 198 ss., con múltiples referencias ulteriores. Y el legislador solo habla, por definición, por medio de la ley. Para una impugnación del recurso a la supuesta "voluntad histórica del legislador" como estándar interpretativo, véase ya BINDING, 1885, pp. 454 y ss.

${ }^{6}$ Acerca del problema bajo la vigencia de la regulación anterior, véase GuZMÁn DALBOrA, 2007, p. 252.

7 Al respecto Mã̃alich, 2015, pp. 516 ss.

${ }^{8}$ Acerca de la orientación del reconocimiento de derechos a animales no humanos bajo la adopción de una posición favorable al "individualismo moral”, fundamental McMahan, 2005, passim. Nótese que la noción de sujeto-de-derecho, así definida, no resulta ser coextensional con la noción de persona, en la medida en que esta última sea entendida como expresiva de un estatus normativo definido por la adscripción de un derecho específico, esto es, el derecho a no ser matado (por otro); véase detalladamente al respecto MAÑALICH, 2014 b, pp. 314 ss., con referencias ulteriores. 


\section{Subjetividad, INTERESES y DERECHOS}

El argumento que habrá de ser presentado en lo que sigue pretende sustentar la tesis de que la noción de sujeto-de-derecho es una que capta adecuadamente el distintivo "estatus moral" que hemos de reconocer, en general, a todo animal del que podemos predicar subjetividad. Esto último encuentra una formulación llamativamente precisa en algunos pasajes que integran el segundo capítulo del primer tomo del monumental Der Zweck im Recht, de Ihering, aparecido en 1884. En efecto, Ihering tematizaba la manera en que la disposición a perseguir objetivos o fines de cierta índole, predicable de animales no humanos, marcaría el "punto de partida para el problema del fin tratándose del ser humano" 9 . Especialmente ilustrativa resulta ser su previa caracterización de los animales no humanos como portadores de lo que, en la jerga de la filosofía de la mente contemporánea, llamaríamos "estados intencionales":

El estado físico de la sed en el paladar no produce como tal el beber, sino solo por la vía de que la presión física o mecánica se transforma en una psicológica, con lo cual el proceso no cae bajo la ley causal, sino bajo la ley de la finalidad. El animal bebe, para suprimir su sed, se abstiene de ello para no recibir un golpe [de su amo]; en ambos casos es la representación de algo futuro lo que impulsa al animal a la acción. [...] Es decir, el animal distingue entre lo que es beneficioso y lo que es perjudicial para su vida, él practica una crítica antes de decidirse, y se vale para ello de las experiencias que ha tenido previamente. Pues al animal no está prefigurado el actuar correcto nada más que mediante el instinto, sino que también el animal se apoya en la experiencia. [...] Así, para el animal existe una experiencia, es decir, un recuerdo de aquello que le es agradable o desagradable, beneficioso o perjudicial, y así también una valoración práctica de sus impresiones para el futuro: un uso propositivo. ${ }^{10}$ [...]

La voluntad se halla tan poco ligada a la autoconsciencia como lo está la vida, y quien ha captado la conexión interna que entre ellas rige, no considerará la idea de que el querer del animal, por la falta de autoconsciencia, no merecería denominarse voluntad y que vindica esta exclusivamente para el ser humano, como profunda, tal como ella quisiera presentarse a sí misma, sino que la tendrá por una idea derechamente superficial y sesgada. Con excepción de la autoconsciencia, que también en el ser humano puede faltar o quedar desactivada, duradera o transitoriamente, las características decisivas de la voluntad humana [...] se repiten también en el animal. Y aun la capacidad de pensar del animal, que es presupuesto de su querer, es infinitamente más alta que lo que parece a primera vista. Se manifiesta así fácilmente: la representación de algo futuro mueve al animal a actuar. ¡Y cuánto yace ya aquí! ${ }^{11}$

\footnotetext{
${ }^{9}$ IHERING, 1884 , pp. 26 ss.

${ }^{10}$ IHERING, 1884, pp. 7 s.

${ }^{11}$ IHERING, 1884, pp. 9 s.
} 
Estas observaciones impresionan, ante todo, por la muy elocuente anticipación de la evidencia hoy disponible acerca de la inequívoca vida mental que muestran tener animales no humanos de variadas especies ${ }^{12}$, pero también por la manera en que ellas vuelven impostergable la pregunta acerca de si, en atención a esa manifestación de la capacidad de ser sujetos de estados intencionales, los animales no humanos tendrían que ser reconocidos como portadores de intereses susceptibles de ser jurídicamente resguardados y promovidos en la forma de auténticos derechos subjetivos, justamente en congruencia con la así llamada "teoría del interés", célebremente defendida por Ihering en la tercera parte de su asimismo monumental Geist des römischen Rechts ${ }^{13}$.

De acuerdo con esta concepción, el sustrato último para el reconocimiento de un derecho subjetivo, entendido como una pretensión correlativa a un deber de otro, solo puede estar constituido por algún interés ${ }^{14}$. Lo que significa: si un sujeto $\mathrm{S}$ tiene un derecho a $\mathrm{X}$, entonces $\mathrm{S}$ ha de tener interés en $\mathrm{X}$. Esta última proposición se deja fundamentar en atención a la estructura formal de un derecho (subjetivo) cualquiera. Si $\mathrm{S}$ tiene un derecho a $\mathrm{X}$, entonces habrá alguien que, en relación con $\mathrm{S}$, tendrá un deber de $\mathrm{X}$, de manera tal que, en virtud de la correlatividad existente entre aquel derecho y este deber, si este resulta infringido aquel resultará vulnerado ${ }^{15}$. En tal caso, y en la medida en que el interés en cuestión resulte suficientemente importante, lo natural sería decir que $\mathrm{S}$ ha sido agraviado por el comportamiento de quien ha infringido el deber correlativo $^{16}$. Pues esto último solo tiene sentido, en efecto, si el incumplimiento de tal deber, correlativo a la vulneración del derecho en cuestión, se corresponde con la afectación de un interés de $\mathrm{S}$.

¿Pero de qué depende que a un individuo pueda atribuirse un determinado interés? La infraestructura de un interés individual ha de estar constituida, mínimamente, por uno o más deseos (o preferencias) atribuibles al individuo en cuestión ${ }^{17}$. Esto se traduce, por de pronto, en que en efecto solo puedan predicarse intereses de entes a los que puedan ser atribuidos estados intencionales, consistentes en deseos, temores, expectativas,

12 De Lora, 2003, pp. 135 ss.
${ }^{13}$ Ihering, 1877 , pp. 302 ss., 317 ss.
${ }^{14}$ Fundamental Feinberg, 1984 , pp. 109 ss.; véase también MaÑaliCH, 2014 b, pp. 316 ss.
${ }^{15}$ Acerca de la correlatividad de las posiciones deónticas susceptibles de ser respectivamente identificadas por medio de las expresiones "derecho" y "deber", tomada la primera stricto sensu -esto es, como equivalente a "pretensión” (claim)-, el locus classicus es HoHFELD, 1919, pp. 35 ss. Al respecto y ulteriormente, el muy riguroso análisis ofrecido por Thomson, 1990, pp. 37 ss., 61 ss. Desde una perspectiva diferente, y distinguiendo entre variados géneros de deberes, no todos definidos por su correlatividad con derechos ajenos, también Feinberg, 1980, pp. 130 ss.

16 La exigencia de que el interés en cuestión resulte ser "suficientemente importante" cumple la función (argumentativa) de hacer reconocible que es posible identificar, como contrapartida, intereses triviales -en cuanto "insuficientemente importantes" de un individuo cuya afectación no puede ameritar la correspondiente tematización de un agravio-. Cuán difícil sea trazar la demarcación entre intereses de uno y otro tipo es algo que no viene al caso examinar aquí, desde ya si en todo caso es posible identificar intereses compartidos por individuos animales de muy diversas especies cuya importancia suficiente se encuentra, para efectos prácticos, más allá de toda genuina discusión.

${ }^{17}$ Véase en detalle Feinberg, 1984, pp. 38 ss., 55 ss. 
creencias, etc., a partir de la constatación de su capacidad para experimentar como deseable la satisfacción de variadas necesidades y como indeseable su falta de satisfacción ${ }^{18}$. Que en general los animales no humanos están en posición de experimentar subjetivamente la realización y la frustración de deseos que les son atribuibles es lo que asume Christine Korsgaard cuando observa que un animal es un ser vivo para el cual algo puede ser bueno o malo, desde su punto de vista ${ }^{19}$. Esto hace posible desambiguar la oración "A tiene interés en $\mathrm{X}$ ", allí donde "A" es un animal cualquiera y "X" designa un estado de cosas cualquiera. Pues que A sea un ser desde cuyo punto de vista $\mathrm{X}$ puede ser bueno no quiere decir, meramente, que la existencia de $\mathrm{X}$ vaya en interés de $\mathrm{A}$, sino más bien que A está interesado en $\mathrm{X}^{20}$. En esto consiste el hecho, destacado por Regan, de que buena parte de los animales no humanos, al igual que la mayor parte de los animales humanos, exhiba, individualmente, la condición de sujeto-de-una-vida, esto es, de alguien -y no meramente algo- que como tal experimenta su vida como propia, y que en tal medida lleva una existencia no solo biológica, sino al mismo tiempo biográfica ${ }^{21}$.

Hasta aquí se ha intentado sugerir que hay razones para pensar que el estatus de sujeto-de-derecho de un individuo cualquiera tiene que hallarse anclado a su condición de portador de intereses susceptibles de ser promovidos y resguardados en la forma de derechos. Pero esto deja abierta la pregunta acerca de qué es posible entender, más precisamente, por "derechos subjetivos". Pues de esto depende a su vez, y según ya se sugiriera, en qué haya de consistir el estatus individual de sujeto-de-derecho. En primer lugar, es necesario advertir que, en la medida en que la adscripción de uno o más derechos subjetivos en sentido propiamente jurídico es algo que tiene lugar mediante mecanismos característicamente institucionales, congruentes con la contingencia y la positividad de todo proceso de "juridificación", es claro que aquí interesa ofrecer un argumento que demuestre que los animales no humanos son titulares, más bien, de derechos (qua pretensiones) en sentido moral, de manera tal que el argumento así construido pueda servir de base para sustentar la alegación de que esos mismos animales no humanos deberían ser reconocidos como titulares de derechos (qua pretensiones) en sentido jurídico ${ }^{22}$. Se

18 Véase ya MaLcolm, 1973, pp. 13 ss., quien pone en cuestión el carácter propiamente proposicional de toda forma de pensamiento, para así ofrecer una respuesta afirmativa a la pregunta de si determinados animales no humanos, desprovistos de la capacidad de interactuar lingüísticamente, "tienen mentes"; en esta dirección, véase también SEARLE, 2002, pp. 61 ss. Acerca de los hallazgos experimentales que avalan el reconocimiento de dominio conceptual a animales no humanos de variadas especies, véase GrIFFIN, 1992, pp. 115 ss., así como los artículos recopilados en LuRz, 2009, passim. Fundamental al respecto, y más recientemente, ANDrEws, 2015, pp. 51 ss., 80 ss., 139 ss.

${ }^{19}$ KorsgaArd, 2005, pp. 103 s.; KorsgaArd, 2012, pp. 12 ss.; Korsgaard, 2013, pp. 642 s.

${ }^{20}$ De Lora, 2003, pp. 141 s.

${ }^{21}$ Regan, 2003 , pp. 80 ss., 92 ss.

${ }^{22}$ Es importante notar que, al hablar de derechos "en sentido jurídico" y "en sentido moral”, y no en cambio de "derechos jurídicos" y "derechos morales", se evita la hipóstasis de postular la existencia de derechos pertenecientes a dos "terrenos" discretos, como si se tratase de dos especies, ontológicamente diversas, de un mismo género; muy iluminadora al respecto Thomson, 1990, pp. 70 ss., 73 ss., quien sugiere que la cuestión se reduce, más bien, a la clase de fundamento susceptible de ser invocado para la adscripción del respectivo derecho, siendo enteramente concebible que un "mismo" derecho se encuentre dualmente fundamentado. 
trata, en tal medida, de un argumento de ética normativa orientado a servir de base para un reclamo de lege ferenda.

Pero en segundo lugar, y restringiendo el análisis a una titularidad sobre derechos en sentido moral, todavía habría que especificar el sentido en que la expresión "derechos morales" está siendo empleada. Siguiendo a De Grazia, es posible diferenciar -a lo menos- tres sentidos en que es posible adscribir el estatus de titular de derechos morales a algún ente cualquiera ${ }^{23}$. En un primer sentido, ser titular de derechos morales equivale, simplemente, a ser un ente que "cuenta moralmente", en términos tales que los intereses que le son atribuibles han de ser tomados en cuenta, de manera que esos intereses no pueden ser legítimamente sacrificados o postergados "sin una buena razón” 24 . En un segundo sentido, más exigente que el anterior, tener derechos morales consiste en ser un ente cuyos intereses quedan sometidos al así llamado "principio de igual consideración”. Esto significa que los intereses de ese individuo "cuentan tanto como los intereses comparables de cualquier otro" ${ }^{25}$. Finalmente, y en un sentido todavía más exigente, ser un ente que es titular de derechos consiste en ser alguien en cuyo nombre es posible esgrimir pretensiones que operen como premisas que invaliden decisiones de mera maximización de bienestar sobre la base de una agregación de intereses o preferencias ${ }^{26}$.

Es justamente en este tercer y último sentido en que recurren a la noción de derechos quienes pretenden hacer reconocible el estatus moral de los animales no humanos en términos de una ética de los derechos, en oposición, por ejemplo, a una ética utilitarista como la favorecida por Peter Singer ${ }^{27}$. Así por ejemplo, Regan caracteriza los derechos susceptibles de ser reconocidos a animales de las más variadas especies como consistentes en "cartas de triunfo", que en cuanto tales puedan ser esgrimidos para impugnar la aceptabilidad moral del sacrificio de los intereses así resguardados en pos de la obtención de algún índice de bienestar agregado ${ }^{28}$.

En estos términos, la sustentación de una ética de los derechos de los animales depende de la demostración de que no hay razón alguna para condicionar la adscripción de derechos subjetivos, en el tercero de los tres sentidos precedentemente diferenciados, a la pertenencia del respectivo animal a una determinada especie, como lo es la del bomo sapiens. Esto exige desvirtuar una objeción que ha sido esgrimida, en general, contra la ya mencionada teoría del interés ${ }^{29}$. De acuerdo con esta objeción, no tendría sentido

\footnotetext{
${ }^{23}$ DE Grazia, 2002, pp. 14 ss.

${ }^{24}$ De GraZia, 2002, p. 15.

25 De Grazia, 2002, p. 15.

${ }^{26}$ De Grazia, 2002, pp. 15 s.

27 Véase Singer, 1993 , pp. 55 ss., 83 ss., 110 ss.; Singer, 2002, pp. 1 ss., 159 ss., 213 ss.

28 Regan, 2004, pp. 16 s. Latamente al respecto, REgan, 2003, pp. 9 ss., 23 ss., 91 ss.; REGAN, 2005, pp. 37 ss., 53 ss.; también Donaldson y KyMlicka, 2011, pp. 19 ss. Al respecto véase también De LORA, 2003, pp. 221 ss., 230 ss., quien acertadamente muestra cómo una ética de los derechos, no siendo compatible con el utilitarismo, sí lo es con determinadas variantes del consecuencialismo, en la medida en que como "mejores estados de cosas" sean identificados "aquellos en los cuales quedan garantizados mayor número de derechos básicos”.

${ }^{29}$ Véase De LORA, 2003, p. 236.
} 
reconocer un derecho subjetivo a un individuo incapaz de hacer valer, por sí mismo, tal derecho. Es crucial reparar, desde ya, en que hay un vicio lógico en pretender hacer depender la existencia de un derecho de la eventual capacidad de su titular para hacerlo valer. Pues la pregunta de si alguien es capaz de hacer valer un derecho presupone, conceptualmente, que ese derecho le haya sido reconocido. Y esto se explica porque la satisfacción de un derecho no depende, necesariamente, de que su titular en efecto logre hacerlo valer, sino más bien de que sea cumplido el deber que le es correlativo. Pero aun con independencia de esta última aclaración, la objeción desconoce flagrantemente la posibilidad de que el respectivo derecho subjetivo sea hecho valer, por cuenta de su titular, por parte de otro, esto es, en el marco de una relación de representación ${ }^{30}$. Y es suficientemente claro que esa posibilidad es sin más asumida tratándose de la posición de animales humanos que son incapaces de hacer valer pretensiones por sí mismos. Con ello, la pregunta pasa a ser si hay algo más que aquella forma de prejuicio o sesgo moral que denominamos "especieísmo" que pueda ser invocado para no hacer extensivo el reconocimiento de derechos subjetivos a animales no humanos, siendo el caso que estos derechos son reconocidos a animales humanos que son incapaces de hacerlos valer por sí mismos ${ }^{31}$.

La pregunta así planteada conduce a la ya usual formulación del llamado "argumento de los casos marginales" ${ }^{32}$. Este funciona mostrando cómo, a partir del reconocimiento de la existencia de casos (precisamente: marginales) en los que se reconoce el estatus de sujeto-de-derecho a individuos de la especie humana que carecen de las capacidades necesarias para contar como agentes morales ${ }^{33}$, se hace necesario concluir, en conformidad con el principio de consistencia que ha de guiar nuestra consideración de situaciones moralmente equivalentes, que lo mismo tiene que valer tratándose de animales de otras especies $^{34}$. Que la resistencia a abrazar esta última conclusión tiende a descansar, en efecto, en la adopción de un prejuicio especieísta, es elocuentemente confirmado por la manera en que Cortina pretende hacer frente a la objeción dirigida contra las éticas antropocéntricas, por negarse estas a "reconocer derechos a los animales y, sin embargo, sí se los reconozcan a los niños, los discapacitados psíquicos y los enfermos en estado vegetativo" ${ }^{35}$. Según Cortina, tal diferenciación antropocéntrica se justificaría por el hecho de que mientras los animales (no humanos) "no tienen la capacidad de entender qué sea un derecho" a la vez que "son miembros de comunidades en que ese discurso carece de sentido", "los discapacitados humanos [...] pertenecen a la especie humana y eso significa que su discapacidad es un defecto y es preciso intentar remediarlo para

${ }^{30}$ FeINBERG, 1980, pp. 162 ss.

31 Acerca del concepto de "especieísmo" y las variantes de este, ofreciendo una adecuada descripción del estado del debate al respecto, véase Morales, 2015, passim.

32 Véase De Lora, 2003, pp. 234 ss.

33 Esta noción es definida y explicada en la sección siguiente; véase infra, 3.

${ }^{34}$ Veáse Regan, 2004, pp. 18 ss.

35 Cortina, 2009, p. 97. 
que sean miembros de la comunidad que les corresponde" 36 . Ergo, sería la pertenencia a la especie humana lo que sustentaría la diferenciación. Res ipsa loquitur.

\section{PACIENCIA MORAL SIN AgENCIA MORAL}

Una versión especialmente prometedora de un argumento favorable al reconocimiento de que los animales no humanos cuentan, en sentido moral, como titulares de derechos ha sido desarrollada por la filósofa kantiana Christine Korsgaard, a quien ya me refiriera. El interés por la contribución de Korsgaard se justifica, desde ya, por el hecho de que se trata de un esfuerzo por anclar el reconocimiento del estatus de los animales no humanos como titulares de derechos en la filosofía moral de Kant, en circunstancias de que Kant mismo desestimó, célebremente, que tuviera sentido predicar de los animales, en cuanto seres irracionales, aquella forma de dignidad exhibida por seres que cuentan como "fines en sí mismos" 37.

Pero la contribución de Korsgaard no solo es merecedora de atención por su apuesta por poner la filosofía de Kant contra Kant, en lo que al estatus normativo de los animales no humanos respecta, sino también -y de manera internamente conectada con lo anterior- por la singular manera en que su argumentación hace uso de la idea según la cual los animales no humanos son seres cuya constitución natural determina que los derechos de los que ellos son titulares solo puedan ser hechos valer, en cuanto pretensiones con capacidad de interpelar y vincular moralmente a otros seres, por vía de representación.

Aquí es imprescindible tomar nota de que, en la senda de Kant, Korsgaard favorece sustituir -a lo menos en los pasos argumentativamente cruciales- la distinción entre animales humanos y animales no humanos por la distinción entre animales racionales y animales irracionales ${ }^{38}$. Korsgaard explica, con todo, que la noción de racionalidad, en el sentido kantianamente relevante, no puede ser confundida con la noción de inteligencia, de manera tal que la falta de racionalidad de un ser cualquiera no implica una falta de inteligencia ${ }^{39}$. Lo distintivo de lo que Kant entiende por "racionalidad" está constituido más bien por una específica forma de autoconsciencia, consistente en "la capacidad para percibir, y por ello para pensar acerca de las razones para nuestras creencias y acciones, como razones" 40 . Esto haría posible que los seres humanos, en cuanto seres racionales, exhiban una capacidad para gobernarse normativamente a sí mismos, de un modo que

36 Cortina, 2009, p. 100.

${ }^{37}$ Para una contextualización, véase Wood, 2008, pp. 85 ss., 101 ss. Acerca del problema, y reconstruyendo caritativamente lo dicho por Kant en la Metafísica de las Costumbres, véase asimismo KAIN, 2010, pp. 210 ss., 219 ss.

${ }^{38}$ Korsgaard, 2005 , pp. 82 ss.; Korsgaard, 2012, pp. 6 ss.; Korsgaard, 2013, pp. 638 ss.

39 KORSGAARD, 2005, pp. 85 s.

${ }^{40}$ KORSGAard, 2005 , p. 85. 
es definitorio de lo que significa ser un agente moral, a saber: un individuo cuyo comportamiento es susceptible de ser guiado y evaluado moralmente ${ }^{41}$.

Esta consideración está en la base de una de las formulaciones alternativas del imperativo categórico que Kant ofrece en la Fundamentación de la metafísica de las costumbres, conocida como la "fórmula de la humanidad" 42 , que reza como sigue:

Actúa de tal manera que tú en todo momento trates la humanidad, tanto en tu persona como en la persona de cualquier otro, al mismo tiempo como un fin, $y$ nunca meramente como un medio ${ }^{43}$.

Pero inmediatamente antes, Kant ha preparado la presentación de esta fórmula sosteniendo que el fundamento del "principio objetivo de la voluntad" en que consiste el imperativo categórico es que "la naturaleza racional existe como fin en sí mismo" ${ }^{4}$, lo que estaría determinado, a su vez, por la siguiente consideración:

Los seres cuya existencia no descansa en nuestra voluntad sino en la naturaleza, no obstante ello, si son seres carentes de razón, tienen solo valor relativo, como medios, y por ello se llaman cosas, en tanto que los seres racionales son llamados personas, porque su naturaleza los distingue ya como fines en sí mismos, esto es, como algo que no puede ser usado meramente como medio $[\ldots]^{45}$.

La fórmula de la humanidad pretende establecer, entonces, que la dignidad propia de todo ente que, por constituir un fin en sí mismo, merece respeto por lo que es, sería estrictamente dependiente de su racionalidad, entendida como su capacidad para gobernarse moralmente ${ }^{46}$. Puesto en una terminología hoy en boga, ello significa que

${ }^{41}$ KorsgaARD, 2005 , p. 87.

${ }^{42}$ Acerca del estatus de cada una de las cuatro fórmulas alternativas del imperativo categórico ofrecidas por Kant, y de las conexiones existentes entre ellas, véase las diferentes propuestas de reconstrucción ofrecidas por Allison, 2011, pp. 176 ss., 204 ss., 237 ss.; Timmermann, 2007, pp. 73 ss., 109 ss.; y Wood, 2008, pp. 66 ss. Al respecto, véase también Tugendhat, 1993, pp. 131 ss., 135 ss.

43 KanT, 1786, AB 66-67.

${ }^{44}$ KANT, 1786, AB 66. Es fundamental advertir la ambigüedad que exhibe el término "fin", en cuanto capaz de designar tanto aquello que un agente (subjetivamente) persigue traer a efecto, por un lado, como aquello que (objetivamente) existe con independencia del actuar del agente, y que reclama reconocimiento de este, por otro. Véase al respecto Timmermann, 2007, pp. 90 ss., 93 s.; Allison, 2011, pp. 208 s., quienes dan cuenta de la necesidad de interpretar la expresión "fin-en-sí-mismo" con arreglo al segundo de los sentidos en que es posible hablar de un "fin". Al respecto, véase también ya KorsGaARD, 1996a, pp. 124 ss.

45 KANT, 1786 , AB 65.

46 Esta manera de presentar el punto conlleva, desde luego, una simplificación, en cuanto es exegéticamente controversial en qué medida un ser que ejemplifica lo que en este contexto Kant entiende por "humanidad" habría de ser equiparado o bien (a) con un agente racional, en cuanto capaz de ponerse fines, o bien (b) con un ser que exhibe una "buena voluntad", o bien (c) con un ser que exhibe "capacidad moral". Véase al respecto Allison, 2011, pp. 209 ss., quien argumenta a favor de la tercera interpretación, a la vez que atribuye la primera a Korsgaard; sobre esto, por su parte, véase KonSGAARD, 1996a, pp. 110 ss. 
Kant aparece así equiparando el estatus de paciente moral, entendido como el estatus de un ser en relación con el que es posible estar obligado, por un lado, con el estatus de agente moral, entendido como el estatus de un ser que puede encontrarse obligado para con alguien, por otro ${ }^{47}$. Tal equiparación fundamenta, entonces, una muy distintiva variante de una "ética de la reciprocidad" ${ }^{8}$ : X solo puede estar obligado para con Y en la medida en que Y pueda, a su vez, estar obligado para con X. De ahí que, según Kant, no sea posible sostener la existencia de deberes directos, sino solo de deberes indirectos, respecto de animales no humanos, esto es, deberes que, aunque se refieren a ellos, no se tienen para con ellos, sino para con (otros) seres racionales ${ }^{49}$. El argumento de Korsgaard se dirige a mostrar que la equiparación que Kant hace de las condiciones de paciente y agente moral es, kantianamente, errada.

La razón por la que solo seres dotados de racionalidad, en el sentido ya explicado, pueden resultar obligados moralmente radica en que, según Kant, el fundamento último de toda obligación moral se encuentra en la autonomía de una voluntad racional de un ser capaz de "legislar" -esto es, de ofrecer razones que reclaman fuerza vinculante- para sí mismo y los demás. La vocación radicalmente secular de la ética kantiana se muestra en su compromiso con la idea de que toda asignación de valor es resultante de la manera en que las elecciones autónomas de seres racionales confieren valor a los objetos de esas mismas elecciones ${ }^{50}$. Formulado más drásticamente, ello quiere decir que, de acuerdo con Kant, en un mundo en el que no existieran seres capaces de juzgar autónomamente no habría valor alguno ${ }^{51}$.

Así, y en cuanto seres racionales, somos nosotros quienes tomamos nuestros propios intereses y nuestras propias preocupaciones como importantes, de un modo que las vuelve efectivamente importantes, en el sentido de que esos intereses y preocupaciones se convierten en la base de pretensiones normativas que dirigimos a nosotros mismos y a otros. Pero de ello no se sigue, observa Korsgaard, que cada uno de nosotros tome sus intereses y preocupaciones como importantes "solamente porque son los intereses y las preocupaciones de un ser racional y autónomo" 52 . A pesar de que es recién mediante nuestra consideración de nosotros mismos como la fuente de cualquier pretensión dotada de obligatoriedad que emerge aquel espacio público de razones y valores que conforma la dimensión normativa del mundo que habitamos, no se sigue de ello que lo que en efecto tratamos como la fuente de esas mismas pretensiones quede reducido a

47 Véase KorsgaArd, 2005, pp. 95 s.; KorsgaARD, 2012, p. 10. En conformidad con lo observado supra, nota 8 , la distinción entre pacientes morales y agentes morales admite ser entendida como una generalización de la distinción entre personas en sentido deóntico (o prescriptivo) y personas en sentido adscriptivo; acerca de esto último véase ya MAÑaliCH, 2014b, pp. 314 s., con n. 33.

${ }^{48}$ En detalle De Lora, 2003, pp. 109 ss.

${ }^{49}$ En detalle al respecto KaIn 2010, pp. 210 s., 220 ss. Véase asimismo De Lora, 2003, pp. 118 ss.; también Cortina, 2009, pp. 68 ss.

${ }^{50} \mathrm{Al}$ respecto, y en detalle, ya KorsgaARD, 1996b, pp. 90 ss., 131 ss.

51 Véase KorsgaARD, 2005, p. 101; más detalladamente ya KorsGaARD, 1996a, pp. 128 ss.

52 KorsgaARD, 2005, pp. 99 s. 
nuestra naturaleza racional ${ }^{53}$. Antes bien, prosigue Korsgaard, que cada uno de nosotros se tome a sí mismo como un fin-en-sí-mismo significa que cada uno de nosotros se encuentra "inclinado a tratar [sus] estímulos naturales como razones", en términos tales que " $[\mathrm{e}] \mathrm{l}$ valor que ponemos en nosotros mismos, como fines-en-sí-mismos, no se expresa meramente en respetar nuestras propias elecciones autónomas, sino también en el contenido de esas elecciones" 54 .

El contenido de esas elecciones se constituye, así, en lo que cuenta como lo bueno para nosotros mismos, desde nuestro punto de vista. Y una parte significativa del contenido de esas elecciones resulta bueno para nosotros mismos en cuanto satisface necesidades e intereses que tenemos no en cuanto animales racionales, sino en cuanto animales sin más. En las muy elocuentes palabras de Korsgaard:

El alimento, el sexo, el bienestar, el estar libre de dolor y miedo, son todas cosas que son buenas para mí en la medida en que soy un ser animado y sintiente. Con ello, es más natural pensar que la pretensión normativa involucrada en elegir racionalmente es que las cosas que son buenas para seres para los cuales las cosas pueden ser buenas o malas han de ser tratadas como buenas o malas, absolutamente ${ }^{55}$.

Lo anterior quiere decir que es nuestra propia naturaleza animal la que determina que haya cosas buenas y malas para nosotros desde nuestro punto de vista, aquello que tratamos como un fin-en-sí-mismo ${ }^{56}$. Pero siendo indudable, agrega Korsgaard, que no somos los únicos seres para quienes las cosas pueden ser buenas o malas en ese mismo sentido, precisamente porque compartimos el mundo con otros animales, tendríamos que estar dispuestos a considerar a todos los animales como fines-en-sí-mismos ${ }^{57}$. Es justamente en este sentido que es posible decir que los animales racionales están capacitados para esgrimir pretensiones con fuerza obligante para nosotros mismos y para otros, esgrimimos esas pretensiones no solo para y por cuenta de nosotros mismos, sino al mismo tiempo en representación de todo animal para el que los objetos de nuestras elecciones y preferencias puedan ser buenos, en el mismo sentido en que lo son para nosotros ${ }^{58}$.

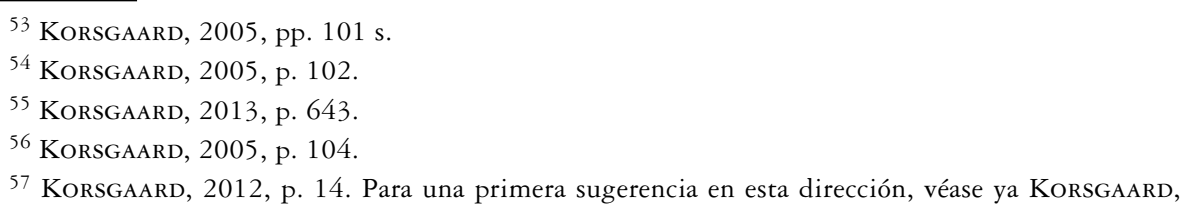
1996b, pp. 145 ss., 149 ss. No deja de ser llamativo que, en su esfuerzo por sostener que los animales (no humanos) carecerían de dignidad, a pesar de exhibir "valor interno", CORTINA, 2009, pp. 173 ss., eche mano al esclarecimiento de las nociones de que algo sea bueno "por-sí-mismo" (en cuanto contrapuesta a la de que algo tenga valor instrumental) y de que algo sea bueno "en-sí-mismo” (en cuanto contrapuesta a la de que algo tenga valor extrínseco), ofrecido en KORSGAARD, 1996a, pp. 249 ss., sin hacer referencia alguna al seminal ensayo de 2005 -aparecido cuatro años antes que el propio libro de Cortina- en el que Korsgaard sustenta la tesis de que los animales no humanos, precisamente por existir como fines-en-sí-mismos, exhibirían dignidad.

58 KorsgaArd, 2013, p. 641. 
En estos términos, la distinción entre aquellos animales que cuentan como agentes y pacientes morales a la vez, por un lado, y aquellos que solo cuentan como pacientes morales, por otro, puede ser reformulada como la distinción entre aquellos animales que cuentan como ciudadanos activos y aquellos que cuentan como ciudadanos pasivos de lo que Kant metafóricamente identifica con un "reino de los fines" 59 . Así como en una república contarían como ciudadanos pasivos aquellos cuyos derechos son protegidos por las leyes del Estado en cuya puesta en vigor, empero, ellos no han tenido incidencia, por no ser titulares de derechos de participación política, siendo entonces los ciudadanos activos quienes legislan, también en interés de aquellos, así también cabría reconocer que, en el dominio de la sola moralidad, existimos animales capaces de producir razones vinculantes no solo para y por cuenta de nosotros mismos, sino asimismo y a la vez por cuenta de otros animales cuya naturaleza no los habilita para hacerlo por sí mismos ${ }^{60}$.

\section{LA SUPERACIÓN DEL BIENESTARISMO COMO EXIGENCIA ÉTICA}

No deja de ser importante advertir que, más recientemente, Korsgaard ha hecho explícito el tránsito que debería llevar desde el reconocimiento del estatus de todo animal capaz de tener intereses como un fin-en-sí-mismo, en sentido moral, hacia la institucionalización de su estatus como sujeto-de-derecho, en sentido jurídico. En lo medular, el argumento para ello se reconduce a la manera en que, en la Metafísica de las Costumbres, Kant hacía referencia a la posesión común de la tierra como presupuesto práctico-racional de la juridicidad de cualquier acto de apropiación originaria de algún pedazo de la tierra por parte de alguna persona en particular ${ }^{61}$. La posibilidad misma de que cualquiera esgrima una pretensión de controlar y disfrutar de alguna porción de la tierra, excluyendo a los demás, depende de que podamos asumir que, con anterioridad a cualquier asignación distributiva, cada uno debe poder invocar un derecho a estar donde sea que esté, donde sea que haya aparecido, contingentemente, "arrojado". Y esta pretensión sustentaría, entonces, la plausibilidad de cualquier reclamo de legitimidad para hacer aprovechables los recursos que encontramos a nuestra disposición en la tierra ${ }^{62}$.

Pero es claro que nosotros no somos los únicos seres sin más opción que la de vivir aquí, en la tierra, haciendo uso de los recursos que encontramos en ella. Esa condición es una que compartimos, nuevamente, con los demás animales que habitan la tierra. Y que los demás animales no estén en condiciones de esgrimir, por ellos mismos, la pretensión de estar donde sea que estén y hacer uso de los recursos con los que ahí se encuentren, no los priva de ser titulares de esa misma pretensión, de manera tal que al esgrimir esa pretensión, para nosotros mismos, tendríamos que estar dispuestos

\footnotetext{
59 Kant, 1786, AB 74-77. Al respecto, véase KorsgaARD, 1996a, pp. 22 ss.

${ }^{60}$ Véase KorsgaArd, 2005, pp. 96, 99 ss.

${ }^{61}$ Kant, 1798, AB 83-84. En detalle al respecto Pinheiro, 2016, pp. 166 ss.

62 KorsgaArd, 2013, pp. 646 s.
} 
a reconocer que la esgrimimos, al mismo tiempo, a nombre de todos los demás animales con quienes compartimos la tierra.

La implicación fundamental del hallazgo de que compartimos la titularidad de semejante pretensión con los animales de otras especies consiste en que ello vuelve inadmisible, sin más, que a estos pretendamos atribuir, más bien, el estatus de recursos disponibles para la realización de nuestros fines. Esto se traduce en que el reconocimiento del estatus normativo de sujetos-de-derecho que compartimos con los animales no humanos debe llevar, sin más, a la abolición de toda forma de propiedad sobre animales.

La falta de realización de esta demanda, impuesta por una condición moral compartida, hace que el progreso involucrado en la transformación de la tipificación del delito de maltrato de animales en un delito de maltrato de animal, que fueran reseñadas al comienzo ${ }^{63}$, deba ser drásticamente relativizado. Pues la tipificación así plasmada no ha desahuciado, en lo más mínimo, el compromiso regulativo con la categorización jurídica de los animales no humanos como objetos de propiedad, esto es, como cosas, así como este último estatus -líricamente especificado como el de cosas muebles "semovientes”- les es atribuido por el art. 567 del Código Civil. Y esto es consistente con que la definición establecida en el nuevo art. 291 ter del Código Penal incluya una cláusula que hace depender el carácter delictivo de la causación de dolor o sufrimiento al animal respectivo a que esa causación sea injustificada, cláusula que -teniendo a la vista algunos antecedentes de derecho comparado- con toda probabilidad habrá de ser interpretada, a contrario sensu, como dando lugar a la irrelevancia típica de formas de comportamiento que, no obstante la causación de dolor o sufrimiento al animal afectado, resulten "socialmente aceptadas" 64 , en atención a su contribución a la satisfacción de necesidades -alimenticias, farmacológicas, cosméticas o estéticas- de seres humanos ${ }^{65}$.

Lo anterior muestra que la reciente innovación legislativa se muestra enteramente comprometida con el paradigma del así llamado "bienestarismo", el que, sustentado en premisas éticas tomadas del utilitarismo, se distingue por no problematizar el sometimiento de los animales no humanos a relaciones de explotación que perpetúan su condición de recursos existentes para la satisfacción de los intereses de los animales humanos ${ }^{66}$. En tal medida, el bienestarismo es irreconciliable con una ética de los derechos que, como la presentada en este trabajo, promueve la adscripción de auténticos derechos subjetivos a todo animal individual que sea portador de intereses. Y es recién en la identificación de quienes pueden ocupar la posición deóntica consistente en el deber correlativo a cualquiera de esos derechos subjetivos que se vuelve reconocible

${ }^{63}$ Véase supra, 1.

${ }^{64}$ En referencia a la tipificación plasmada en el art. 337 del Código Penal español, así Hava García, 2011, pp. 300 s.; críticamente al respecto ya García Solé, 2010, pp. 40 s.

${ }^{65}$ Así, y en referencia a la exigencia regulativa del carácter "innecesario" del sufrimiento irrogado bajo la legislación orientada a prevenir y reprimir la "crueldad" contra los animales no humanos en el contexto de la tradición del common law y del derecho estadounidense, Francione, 1995, pp. 17 ss., 119 ss., 134 ss.

${ }^{66}$ Fundamental Francione, 1995, pp. 3 ss.; Francione, 2008, pp. 1 ss., 25 ss. Francione, 2010, passim. 
nuestra (en todo caso provisoria) singularidad moral en cuanto agentes morales ${ }^{67}$. Pues esa singularidad se reduce a que somos los únicos animales dotados de la capacidad para obligarnos a respetar a cada animal, humano o no humano, capaz de experimentar lo que le ocurre como bueno o malo para sí mismo, desde su propio punto de vista.

\section{BIBLIOGRAFÍA}

Alexy, Robert, 1991: Theorie der juristischen Argumentation, 2a ed., Fráncfort del Meno: Suhrkamp. Allison, Henry, 2011: Kant's Groundwork for the Metaphysics of Morals, Oxford y Nueva York: Oxford University Press.

ANDREws, Kristin, 2015: The Animal Mind, Londres y Nueva York: Routledge.

Binding, Karl, 1885: Handbuch des Strafrechts, Léipzig: Felix Meiner.

Contina, Adela, 2009: Las fronteras de la persona, Madrid: Taurus.

De Grazia, David, 2002: Animal Rights, Oxford: Oxford University Press.

De Lora, Pablo, 2003: Justicia para los animales, Madrid: Alianza.

Donaldson, Sue y Kymlicka, Will, 2011: Zoopolis. A Political Theory of Animal Rights, Oxford: Oxford University Press.

Feinberg, Joel, 1980: Rights, Justice, and the Bounds of Liberty, Princeton (N.J.): Princeton University Press.

Feinberg, Joel, 1984: Harm to Others, Oxford y Nueva York: Oxford University Press.

Francione, Gary, 1995: Animals, Property, and the Law, Filadelfia: Temple University Press.

Francione, Gary, 2008: Animals as Persons, Nueva York: Columbia University Press.

Francione, Gary, 2010: "The Abolition of Animal Exploitation”, en Gary Francione y Robert Garner, The Animal Rights Debate, Nueva York: Columbia University Press, pp. 1-102.

García Solé, Marc, 2010: "El delito de maltrato a los animales. El maltrato legislativo a su protección”, Revista de Bioética y Derecho 18, pp. 36-43.

Griffin, Donald, 1992: Animal Minds, Chicago y Londres: The University of Chicago Press.

GuZmán Dalbora, José Luis, 2007: Estudios y defensas penales, Santiago: LexisNexis.

Hava García, Esther, 2011: "La protección del bienestar animal a través del derecho penal", Estudios Penales y Criminológicos 31, pp. 259-304.

Hohfeld, Wesley, 1919: Fundamental Legal Conceptions, New Haven: Yale University.

IHERING, Rudolf, 1877: Geist des Römischen Rechts, parte tercera, $3^{\mathrm{a}}$ ed., Léipzig: Breitkopf \& Härtel. IHERING, Rudolf, 1884: Der Zweck im Recht, tomo II, 2 a ed., Léipzig: Breitkopf \& Härtel.

KaIN, Patrick, 2010: "Duties regarding animals", en Denis (ed.), Kant's Metaphysics of Morals, Cambridge: Cambridge University Press, pp. 210-233.

Kant, Immanuel, 1786: Grundlegung zur Metaphysik der Sitten, Werkausgabe VII, Fráncfort del Meno: Suhrkamp.

Kant, Immanuel, 1798: Die Metaphysik der Sitten, Werkausgabe VIII, Fráncfort del Meno: Suhrkamp.

Korsgaard, Christine, 1996a: Creating the Kingdom of Ends, Cambridge: Cambridge University Press.

KorsgaARd, Christine, 1996b: The Sources of Normativity, Cambridge: Cambridge University Press.

67 Véase supra, nota 15. 
Korsgaard, Christine, 2005: "Fellow Creatures: Kantian Ethics and Our Duties to Animals", The Tanner Lectures on Human Values, vol. 25, Salt Lake City: The University of Utah, pp. 77-110.

Korsgaard, Christine, 2012: “A Kantian Case for Animal Rights”, en Michel, Kühne y Hänni (eds.), Animal Law - Tier und Recht, Zúrich y St. Gallen: Dike, pp. 3-27.

Korsgand, Christine, 2013: "Kantian Ethics, Animals, and the Law", Oxford Journal of Legal Studies 33, $\mathrm{N}^{\circ}$ 4, pp. 629-648.

Lurz, Robert (2009): The Philosophy of Animal Minds, Cambridge: Cambridge University Press.

Malcolm, Norman, 1973: "Thoughtless Brutes", Proceedings and Addresses of the American Philosophical Association 46, pp. 5-20.

MaÑalich, Juan Pablo, 2014a: "Omisión del garante e intervención delictiva", Revista de Derecho Universidad Católica del Norte 21, N² 2, pp. 225-276.

MaÑalich, Juan Pablo, 2014b: "La permisibilidad del aborto como problema ontológico", Derecho y Humanidades 23, pp. 305-333.

MaÑalich, Juan Pablo, 2015: "La reiteración de delitos como concurso real. Sobre la conmensurabilidad típica de los hechos concurrentes como criterio de determinación de la pena”, Política Criminal 10, No 20, pp. 498-527.

MaÑalich, Juan Pablo, 2017: "Responsabilidad, autoridad y democracia: una exploración crítica de la filosofía del derecho penal de Antony Duff”, Discusiones XVII, pp. 167-219.

McMahan, Jeff, 2005: "Our Fellow Creatures", The Journal of Ethics 9, pp. 353-380.

Morales, Héctor, 2015: "La resistencia de la objeción especista”, Derecho y Crítica Social 1, No 2, pp. 375-410.

Pinheiro, Alice, 2016: "Common Possession of the Earth and Cosmopolitan Right", KantStudien 107, pp. 160-178.

Regan, Tom, 2003: Animal Rights, Human Wrongs, Oxford: Rowman \& Littlefield.

Regan, Tom, 2004: “The Day May Come: Legal Rights for Animals”, Animal Law 10, pp. 11-24.

Regan, Tom, 2005: Empty Cages. Facing the Challenges of Animal Rights, Oxford: Rowman \& Littlefield.

SeArle, John, 2002: Consciousness and Language, Cambridge: Cambridge University Press.

Singer, Peter, 1993: Practical Ethics, $2^{\mathrm{a}}$ ed., Cambridge: Cambridge University Press.

Singer, Peter, 2002: Animal Liberation, $3^{\mathrm{a}}$ ed., Nueva York: HarperCollins.

Thomson, Judith Jarvis, 1990: The Realm of Rights, Cambridge (Mass.) y Londres: Harvard University Press.

Timmermann, Jens, 2007: Kant's Groundwork of the Metaphysics of Morals, Cambridge: Cambridge University Press.

Tugendhat, Ernst, 1993: Vorlesungen über Ethik, Fráncfort del Meno: Suhrkamp.

Wood, Allen, 2008: Kantian Ethics, Cambridge: Cambridge University Press.

\section{Normas jurídicas citadas}

Código Penal de la República de Chile.

Código Civil de la República de Chile.

LEY N $\mathrm{N}^{\circ} 20.380$, sobre protección de animales, publicada el 3 de octubre de 2009.

LEY $\mathrm{N}^{\circ} 21.020$, sobre tenencia responsable de mascotas y animales de compañía, publicada el 2 de agosto de 2017.

Código Penal del Reino de España. 
